\title{
Polyurethane Nanocomposites
}

\author{
Igor V. Khudyakov ${ }^{\mathrm{a}}$, R. David Zopf ${ }^{\mathrm{a}}$ and Nicholas J. Turro ${ }^{\mathrm{b}, *}$ \\ ${ }^{a}$ Bomar Specialties, Torrington, CT 06790, USA \\ ${ }^{\mathrm{b}}$ Chemistry Department, Columbia University, New York, NY 10027, USA
}

\begin{abstract}
This review describes the present state of science and technology of photopolymerizable (UV-curable) polyurethane (PU) nanocomposites which include nanosilica and organically-modified clay (organoclay). A number of documented improvements of properties of PU nanocomposites compared to the pristine PU are presented. Many data on the structure and properties of PU nanocomposites were obtained not only for UV-cured urethane acrylate oligomers, but also for nanocomposites produced in the dark reactions. These data are critically reviewed. There is an expectation in the field of dramatic improvement of properties of PU nanocomposites under low loading (1-5 wt \%) of organoclay.
\end{abstract}

(c) Koninklijke Brill NV, Leiden, 2009

\section{Keywords}

Polyurethane, organoclay, UV-cure, nanosilica, nanocomposite, montrillomonite

\section{Introduction}

Nanocomposites are polymers containing nanofillers [1-3]. The microstructure of nanocomposites has inhomogeneities in the scale range of nanometers. Nanocomposite materials cover the range between inorganic glasses and organic polymers [4]. Fillers of polymers have been used for a long time with the goal of enhanced performance of polymers, and especially of rubber. The present paper provides a brief critical review of the literature and some our results on polyurethane (PU) nanocomposites studies. Polymer-clay nanocomposites were reported in the literature as early as 1961 [5]. Nanocomposites demonstrate often unusual and beneficial for the user properties. Scientific and technical literature report the improvement or enhancement of properties of polymer nanocomposites compared to the pristine polymers. This vague statement means an improvement of polymer properties from the standpoint of polymer application. However, different applications may have

\footnotetext{
* To whom correspondence should be addressed. E-mail: njt3@columbia.edu
} 
quite different if not opposite requirements. Increase of polymer toughness $\left(\mathrm{J} / \mathrm{m}^{3}\right)$ is always considered as an improvement.

\section{Types of Nanocomposites}

Two types of nanofillers are under active investigation: nanoparticles and nanoclays. The main paradigm is that a valuable nanocomposite is one with the largest possible surface of nanofiller. In practice it means avoiding aggregation of nanoparticles and exfoliation of nanoclays, see below. Nanoparticles are commercially available from different sources. Sols of nanosilica as colloid solutions in water or in organic solvents are used in preparation of PU nanocomposites. Fumed silica is available as individual particles ranging from $10-20 \mathrm{~nm}$ to micrometers, and can be more or less successfully dispersed in a polymer $[6,7]$.

Layered alumosilicates clays and especially montrillomonite (bentonite) are widely used in nanocomposites. Silicates have a characteristic distance between galleries of $1 \mathrm{~nm}$; the basal spacing of a gallery is also $c a .1 \mathrm{~nm}$. Inorganic cations like $\mathrm{Na}^{+}$between galleries hold negatively charged galleries together. The replacement of the inorganic cations in the galleries of the native clay by alkylammonium (onium) salts or quarternary amines with long alkyl substituents (surfactants) leads to a better compatibility between the inorganic clay and hydrophobic polymer matrix. The replacement leads to an increase of the space between galleries facilitating intercalation of polymer molecules into the clay. Unless stated otherwise, in this paper we will describe only such onium salt modified montrillomonites. We term them organoclay. Three main types of nanocomposites are schematically presented in Fig. 1.

In most cases exfoliated nanocomposites with a high aspect ratio demonstrate enhanced properties compared to the same pristine polymers or polymer with smectic clay. Usually the exfoliation of clay nanolayers in a polymer matrix requires polarity match between the clay surface and the prepolymer precursors to allow optimal access to the gallery [10]. There is a number of ways to increase a degree of exfo-

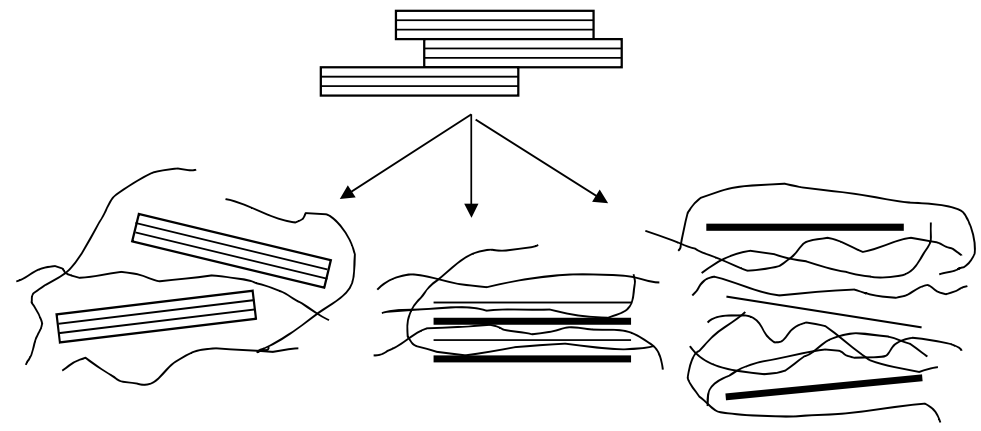

Figure 1. A common pictorial presentation of three types of polymer composites with clay (top). Bottom left, conventional composite; bottom center, intercalated nanocomposite; bottom right, exfoliated nanocomposite. After Refs [3, 8, 9]. 
liation in a nanocomposite, such as in situ polymerization, melt blending, solution blending, sonication, high shear mixing, melt intercalation, and some others $[2,10]$. The morphology of nanocomposites is usually studied by X-ray techniques (XRD), transmission electron microscopy (TEM) and scanning electron microscopy (SEM) [11].

\section{PU-Nanosilica Composites}

PU nanocomposites with colloidal silica and alumina were prepared and their physical properties were studied [12-15]. The following is a straightforward way of preparation of nanocomposites. Colloidal silica of in organic solvent is blended with polyol, organic solvent is stripped off, and one obtains a sol of nanosilica in polyol. After that, polyol with silica reacts with diisocyanate with a formation of PU. The loading by nanosilica in some experiments was as high as $50 \mathrm{wt} \%$ [1214]. Silica sol can be added to monomers at the stage of polyester preparation by polycondensation [16]. Nanosilica in PU can be prepared by in situ hydrolysis and condensation of silane-terminated oligomers [15]. Note that everything should be done to avoid agglomeration of nanoparticles.

Some beneficial properties of silica nanocomposites of PU were observed. Storage moduli of elastomers with nanosilica demonstrated an increase in the rubbery region with increasing filler content [12]. The density of PU nanocomposites is lower than the density of microcomposites (with distributed silica particles of $\mu \mathrm{m}$ size) under the same loading (in wt\%) [12]. Nanosilica has a profound effect on tensile strength of PU composites under a high load $[9,12,13]$. Elongation-at-break of PU nanocomposites demonstrated a strong dependence on a level of nanosilica. A pronounced effect of nanosilica on physical properties of PU nanocomposites was observed under load of 10-20 wt $\%[12,13]$.

A dependence of physical properties of PU with nanosilica of different particle size was studied [15]. It was found that maximum values of the glass-transition temperature $\left(T_{\mathrm{g}}\right)$, tensile properties and abrasion resistance were obtained when the particle size of silica was about $28 \mathrm{~nm}$ [15].

We were interested in the increase of abrasion resistance of the UV-cured urethane acrylates oligomers upon addition of colloidal silica. Colloidal silica of Nissan was added as a solution in methyl ethyl ketone (MEK) to polyol; MEK was stripped off, cf., the beginning of this section. We obtained $6.0 \mathrm{wt} \%$ of silica on solids in urethane acrylates oligomers. We did not observe any increase of abrasion-resistance of the UV-cured coating within the accuracy of our measurements. Apparently surface concentration of nanoparticles was too low to affect abrasion.

No regular dependences are observed in one or another property of PU upon loading of nanoparticles. It was noticed, 'no regular pattern can be said to be emerging' [14]. Usually these dependencies, 'property-loading', have at least one maximum or minimum. 


\section{PU-Organoclay Composites}

A very impressive industrial application of nanocomposites was demonstrated by the Toyota Group in 1988 (see, e.g., Ref. [17]). By using organoclay, they were able to polymerize $\varepsilon$-caprolactam in the interlayer gallery region of clay to form Nylon 6-clay hybrid. At a loading of only $4.2 \mathrm{wt} \%$ the tensile modulus doubled, the tensile strength increased more than 50\%, and heat distortion temperature (HDT) increased by $80^{\circ} \mathrm{C}$ compared to the pristine polymer. The key to this extraordinary performance of Nylon 6-clay nanocomposites was explained as the complete exfoliation of the clay nanolayers in the polymer matrix [17]. This remarkable result stimulated many chemists to search for dramatic improvement of polymer properties upon addition of low level of organoclay.

The effects of organoclays on the properties of PU were studied [1, 3, 18-33]. PU were prepared by the following procedures: (i) distribution of clay in polyol with a subsequent reaction with diisocyanate; (ii) interaction of PU with clay in organic solvent with a subsequent evaporation of solvent; (iii) reaction of diisocyanate with hydroxyalkyl groups of organic modifier in the clay with a subsequent reaction with polyol.

PU nanocomposites prepared with 1-6 wt $\%$ of clay demonstrate peaks on XRD patterns with a distance between galleries (basal spacing) in the range of 1.6-3.2 nm depending on the clay nature and its level [18]. It is possible to conclude based on XRD and SEM and other spectroscopy, that polymer intercalated into the organoclay, it is not exfoliated, and organoclay is not homogeneously dispersed in a PU matrix [18]. Many composites with an added non-exfoliated clay still demonstrate improved mechanical and physical properties and thermal stability, lower permeability of dioxygen compared to the pristine PU [18]. At the same time presented data of property $v s$ organoclay level are not simple in a series of similar nanocomposites: it can be a curve with a maximum (minimum), it can be a permanent decrease or an increase of a property. This confirms the statement made in the previous section on the lack of a regular pattern in property $v s$ nanofiller load [18].

It is documented that high temperature resistance of PU nanaocomposites is higher than that of pristine PU [18, 19, 27, 30, 33].

Wang and Pinnavaia prepared PU nanocomposites by solvation of organoclay by polyol first. Loading of polyol with clay up to $10-20 \mathrm{wt} \%$ makes a pourable mixture [19]. XRD demonstrates that intercalation of polyol into clay results in an increase of with basal spacing from 1.8-2.3 nm to 3.2-3.9 nm [19]. Such spacing testifies of intercalation of polyol into clay. Formation of PU results in further increase of basal spacing up to more than $5 \mathrm{~nm}$ [19]. The latter case may be considered as exfoliation of a clay or dispersal of nanolayers. Important, that onium ions of the clay were considered as active reagents for coupling with diisocyanate [19]. Loading of PU with 5-10 wt $\%$ of clay results in a two-three times improvement of tensile properties of a polymer, namely increase of strain-at-break, tensile modulus and tensile strength [19]. 
Common inorganic fillers are commonly used in PU chemistry to reduce formation cost and to increase stiffness, but the improvements in modulus for conventional PU composites are compromised by a sacrifice of elastomer properties. The nanocomposites reported in Ref. [19] exhibited an improvement in both elasticity and tensile modulus. Clay nanolayers, even when aggregated in the form of intercalated tactoids, strengthen, stiffen and toughen the matrix in the studied case. The enhancement in strength and modulus is directly attributed to the reinforcement provided by the disperse clay nanolayers. The improvement in elasticity is tentatively attributed to the plasticizing effect of onium ions, which contribute to dangling chain formation in the matrix, as well as to conformational effects on the polymer at the clay-matrix interface.

A complete exfoliation of nanoclay was observed in PU nanocomposites with high concentration of nanoclay (up to 40\%) [23]. In this work organoclay was additionally functionalized with diamine, which served a chain extender under PU nanocomposite formation. Tensile strength and elongation-to-break reaches maximum at $5 \mathrm{wt} \%$ of nanofiller loading [23]. Another study of PU nanocomposites demonstrates that the maximum values of flexural and tensile strengths are obtained at only few percent of a clay content [26]. Several PU nanocomposites prepared in [18] were studied in the range of organoclay loading of 0-8 wt\%. Tensile properties demonstrate optimal properties at 3-4 wt\% loading by different organoclays. Ultimate strength and initial modulus have increased in nanocomposites, as well as increased gas barrier properties, the thermal stability of one nanocomposite only increased with increasing clay content [18].

A gradual increase of tensile strength with clay content increase up to $5 \mathrm{wt} \%$ of PU nanocomposites and only slight increase of glass-transition temperature $\left(T_{\mathrm{g}}\right)$ and slight increase of thermal stability was observed for PU nanocomposites prepared in Ref. [31]. It was concluded based on WAXD and TEM that PU intercalated into clay galleries [31].

Organically-treated synthetic fluoromica, which is a layered silicate as well, of different size has a modest effect on the properties of PU nanocomposites [3]. Exfoliated in a solvent unmodified clay laponite as a hydrophilic compound interacts with polar soft segments (polyol) in PU like poly(ethylene oxide) or poly(propylene oxide) where as in PU with hydrophobic soft segments like poly(tetramethylene oxide) clay interacts with the hard domain (urethane links) [24]. Thus, in the first case a decrease toughness and elongation-to-break is observed, whereas in the second case an increase of the same properties is observed [24]. Such a study gives a better understanding of the nanoclay effect of PU nanocomposites properties.

It is reasonable to expect that the formation of PU nanocomposites leads not only to improvement of all valuable for the user properties of the pristine PU. The PU nanocomposites studied in Ref. [27] demonstrated an increase in the elasticity, decrease in damping property, significant increase in thermal stability but demonstrated also a decrease of tensile modulus. Hysteresis results indicate that energy dissipation increases with an organoclay concentration increase [27]. Films 
of radiation-curable urethane acrylates demonstrate minor variation of Young's modulus and tensile strength upon dispersion of organoclay in formulations in the concentration up to $5 \mathrm{wt} \%$ [28].

Some onium salts of organoclay have $\omega$-hydroxyalkyl substituents. The HO$\mathrm{CH}_{2}-$ group can be used to react with isocyanate and, that way, to drag OCN-R between galleries or at least strengthen the interaction between urethane pre-polymer and clay $[29,30]$. A twofold increase of tensile strength and tensile modulus in exfoliated nanocomposites was obtained [29]. In a quite similar way PU nanocomposites are formed by a reaction of IPDI not only with polyol but with $\mathrm{HO}-\mathrm{CH}_{2}-$ groups within galleries. Probably nanocomposites have an intercalated structure [34].

PU nanocomposites with the photoinitiator (PI) 2-hydroxy-2-methyl-1-phenylpropane-1-one (Darocur 1173) were prepared [30]. This PI-PU nanocomposite was dispersed in polymerizable resins. Such initiator manifested high efficiency. XRD and TEM demonstrated formation of intercalated and exfoliated UV-cured nanocomposites with many good characteristics [30]. Photopolymerization occurs inside the organoclay galleries [30].

PU, as well as a number of other polymers, can demonstrate shape recovery after temporary applied stress (shape memory). PU nanocomposites demonstrated the lowest relaxation rate after removal of a stress $1 \mathrm{wt} \%$ of organoclay. The studied PU nanocomposites manifested the highest degree of clay exfoliation namely at $1 \mathrm{wt} \%$ [33]. PU nanocomposites with 3 and $5 \mathrm{wt} \%$ of organoclay relaxed faster than the pristine PU [33].

A profound improvement of properties PU foam upon addition of $5 \mathrm{wt} \%$ of organoclay was observed [35].

We used organoclay Cloisite ${ }^{\circledR} 15 \mathrm{~A}$ of Southern Clay Products [36] as received. A distance between the galleries in the Closite is $3.15 \mathrm{~nm}$ [21, 22]. Urethane acrylate oligomers were prepared the usual way: a reaction of polyol with diisocyanate with a subsequent capping of non-reacted isocyanate groups by $\omega$-hydroxyalkyl acrylates. Prior to that Cloisite was dispersed in polyol by prolong high shear mixing. Unfortunately, this Cloisite and several other studied nanoclays of a similar structure efficiently catalyze di- and, especially trimerization of common isocyanates at elevated temperatures [37]:

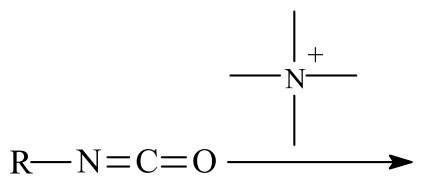<smiles>[R]n1c(=O)n([R])c(=O)n([R])c1=O</smiles>

Formation of isocyanurate in the case of common diisocyanates TDI and IPDI was demonstrated by IR, with characteristic peaks at $1695-1715 \mathrm{~cm}^{-1}$ [29]. Polyol with dispersed organoclay and diisocyanates transforms into a solid or a very viscous 


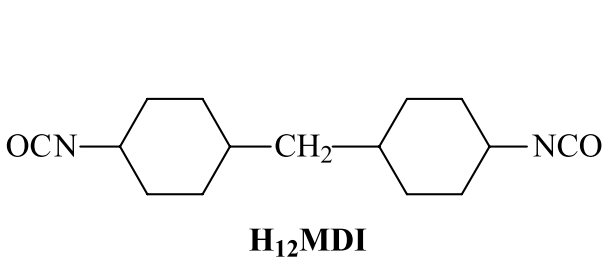<smiles>CC(C)(N=O)c1cccc(C(C)(C)[N+](=O)[O-])c1</smiles>

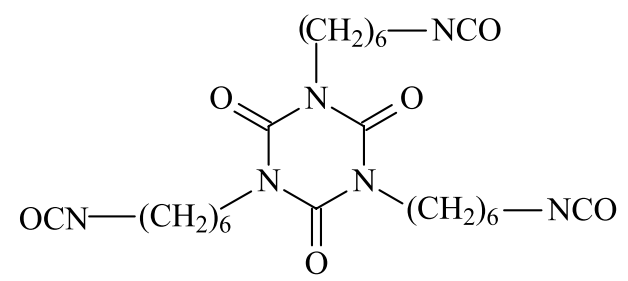

HDI Trimer

Scheme 1. Common polyisocyanates and their abbreviated names.

product. We have found that among several common commercially available polyisocyanates only those presented in Scheme 1 do not react with itself and/or with clay under solventless preparation of PU nanocomposites.

To the best of our knowledge, most of the publications, except Ref. [19], do not report disappearance of $-\mathrm{NCO}$ in the presence or organoclay by reaction (1). We believe that reaction (1) is a serious hurdle in the synthesis of PU nanocomposites.

Below we will discuss the properties of urethane acrylate oligomer prepared from a trifunctional polyol, $\mathrm{H}_{12} \mathrm{MDI}$ (Scheme 1) and 2-hydroxylethyl acrylate as a capping agent. We will name this oligomer UAO. UAO had 0-20.0 wt\% of Cloisite ${ }^{\circledR}$ $15 \mathrm{~A}$. We studied UAO as a viscous liquid and as a UV-cured in the presence of a photoinitiator film. Figure 2 presents XRD data on the cured UAO.

The following peak locations $2 \theta$ and corresponding spacing (in $\mathrm{nm}$ ), presented in parentheses, were observed: $0.25^{\circ}(35.3) ; 1.4^{\circ}(6.3) ; 2.3^{\circ}(3.8) ; 4.3^{\circ}(2.1) ; 7.0^{\circ}$ (1.3). Interesting is the absence of a maximum at $2.8^{\circ}(3.15 \mathrm{~nm})$ of basal spacing in individual Closite ${ }^{\circledR} 15 \mathrm{~A}$ (see above). XRD study gives info on the nanocomposite. Lack of the maxima will mean the complete exfoliation of clay or a high disorder of clay. However, several maxima are observed in Figs 2 and 3. A peak at $2 \theta=0.25^{\circ}$ is very close to the direct beam and may be spurious. A broad hump at $2 \theta=20^{\circ}$ (approx. $0.4 \mathrm{~nm}$ ) is consistent with the bulk polymer portion of a sample. Most probably distances of 3.8 and $6.3 \mathrm{~nm}$ correspond to the intercalated PU acrylate. TEM and SEM will be used used in addition to XRD to get more accurate picture.

We have studied rheology of urethane acrylate nanocomposites with $0,3.2,10.0$ and $20.0 \mathrm{wt} \%$ of Closite ${ }^{\circledR}$ 15A with an ARES (Advanced Rheometric Expansion System) Rheometer. Measurements were done in the rate sweep, dynamic strain sweep and dynamic frequency sweep modes. 


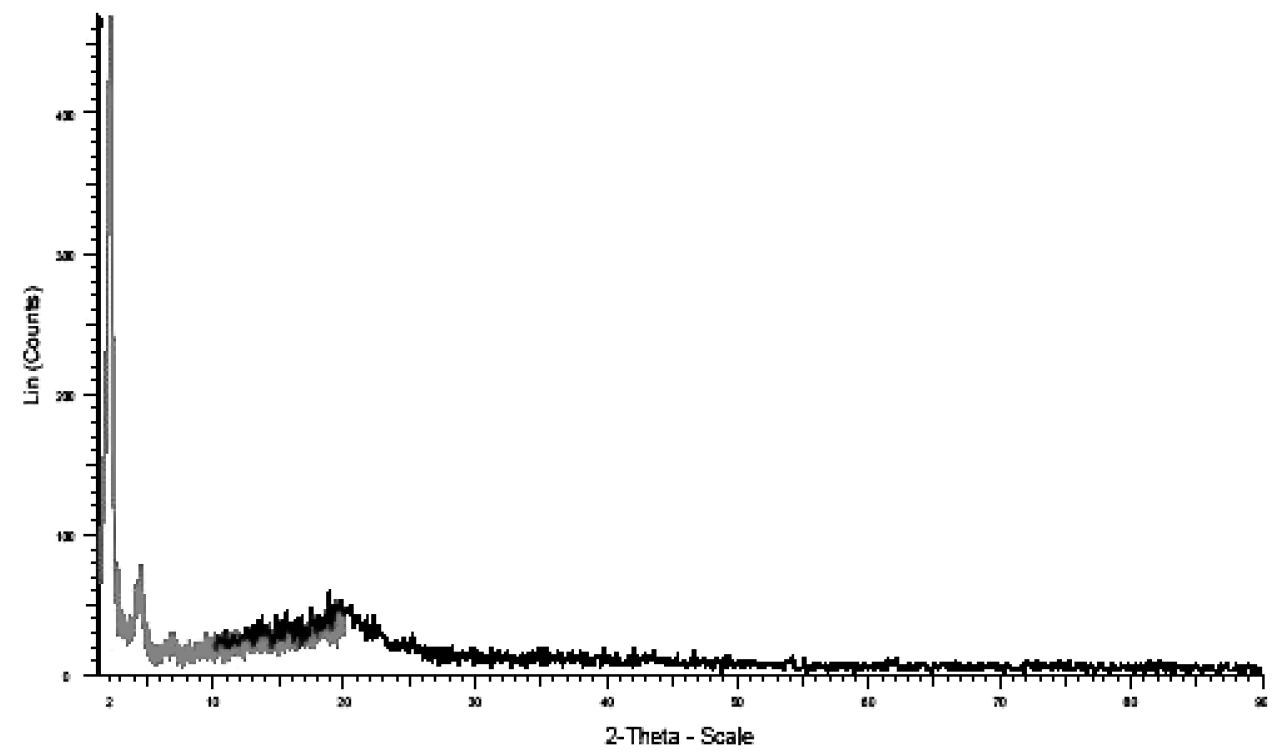

Figure 2. Small- (the left curve) and wide-angle X-ray scatter (the right curve) XRD patterns of UV-cured UAO with $10 \mathrm{wt} \%$ of Closite ${ }^{\circledR} 15 \mathrm{~A}$.

Figure 4 demonstrates the expected pseudoplastic rheological behavior. Figure 5 shows a maximum, which most probably reflects reversible agglomeration of distributed organoclay particles. At low shear rates particles bump into each other and stick, causing an increase of viscosity. At higher shear rates, these loose agglomerates break up. In general, rheological measurements revealed a rather complex behavior of UAO/Cloisite nanocomposites.

We compared the physical properties of UV-cured two UAO films: with 0 and with $10 \mathrm{wt} \%$ organoclay. We did not observe significant changes in tensile properties and in $T_{\mathrm{g}}$ of the two samples. UAO with $10 \mathrm{wt} \%$ organoclay finds an application in low gloss furniture coatings. Macroscopic gloss measurements of cured films of $\mathrm{UAO} /$ organoclay demonstrated a marked decrease in surface gloss, proportionate with clay concentration ( 15 G.U. at $60^{\circ}$ with $4 \mathrm{wt} \%$ clay, $v s 90$ G.U. at $60^{\circ}$ for pristine cured UAO). Unlike the incorporation of common fumed silica matting agents, the resulting matte finishes were highly resistant to burnishing. It is theorized that intercalated clay particles are embedded in the cured polymer matrix with some of the added durability expected of fully exfoliated organoclay, and yet are sufficiently abundant and proximate so as to have a visual impact on cured film optical properties.

\section{Conclusions and Perspectives}

In the present article we aimed to describe the current status of PU nanocomposites research. Colloidal silica and organoclays are the most studied nanofillers which often reinforce PU. The advantage of nano-scale reinforcement is twofold: (1) when 


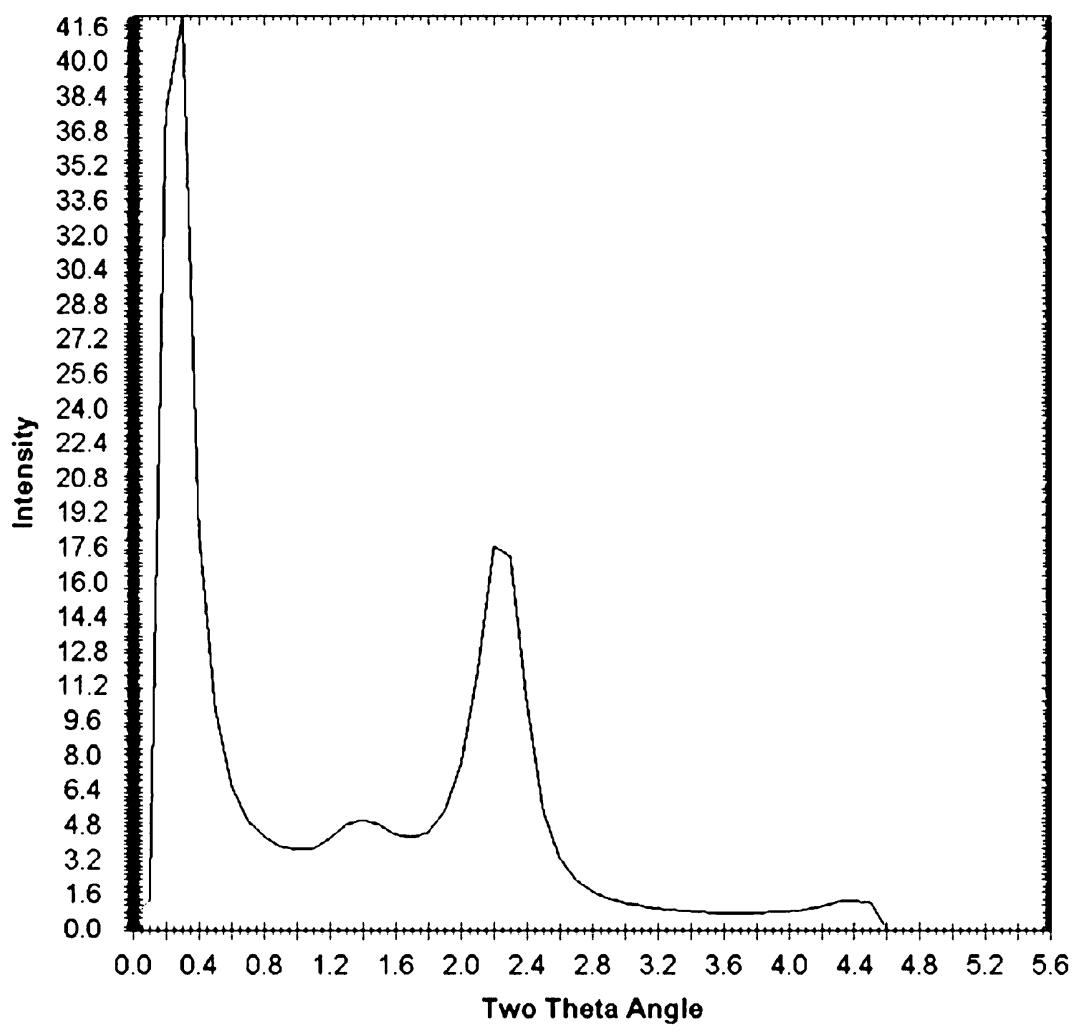

Figure 3. Expanded small-angle X-ray scatter curve of Fig. 2.

nano-scale fillers are homogeneously dispersed in the matrix, a tremendous surface area developed that could contribute to polymer chain confinement, which may lead to higher $T_{\mathrm{g}}$, higher stiffness and tensile strength, increased elongation and an increase of both flexural and tensile modulus, higher HDT, and (2) nanoscale fillers, especially clays, provide an extraordinary zigzag tortuous diffusion path that lead to enhanced barriers for gas penetration for a gas (dioxygen, others), moisture. The enhanced barrier characteristics, chemical resistance, reduced solvent uptake and flame retardancy of clay-polymer nanocomposites originates from the hindered pathways through the nanocomposite [2, 9]. Usually nanocomposites possess special properties not shared by conventional composites, due primarily to large interfacial are per unit volume or mass of the dispersed phase (e.g., $750 \mathrm{~m}^{2} / \mathrm{g}$ [2]). Current status of nanoscience and nanotechnology does not allow prediction of the 'good' formulations and properties of nanocomposites. Chemist/technologist addresses to the prior art and analogies developing nanocomposites, or runs an exploratory work.

Improved properties of some PU nanocomposites with silica can be obtained under high load of the latter, namely 10-50 wt\% [14]. Organoclay can be properly dissolved in the level of 3-10 wt $\%$ in order to obtain enhanced performance $[18,19]$. 


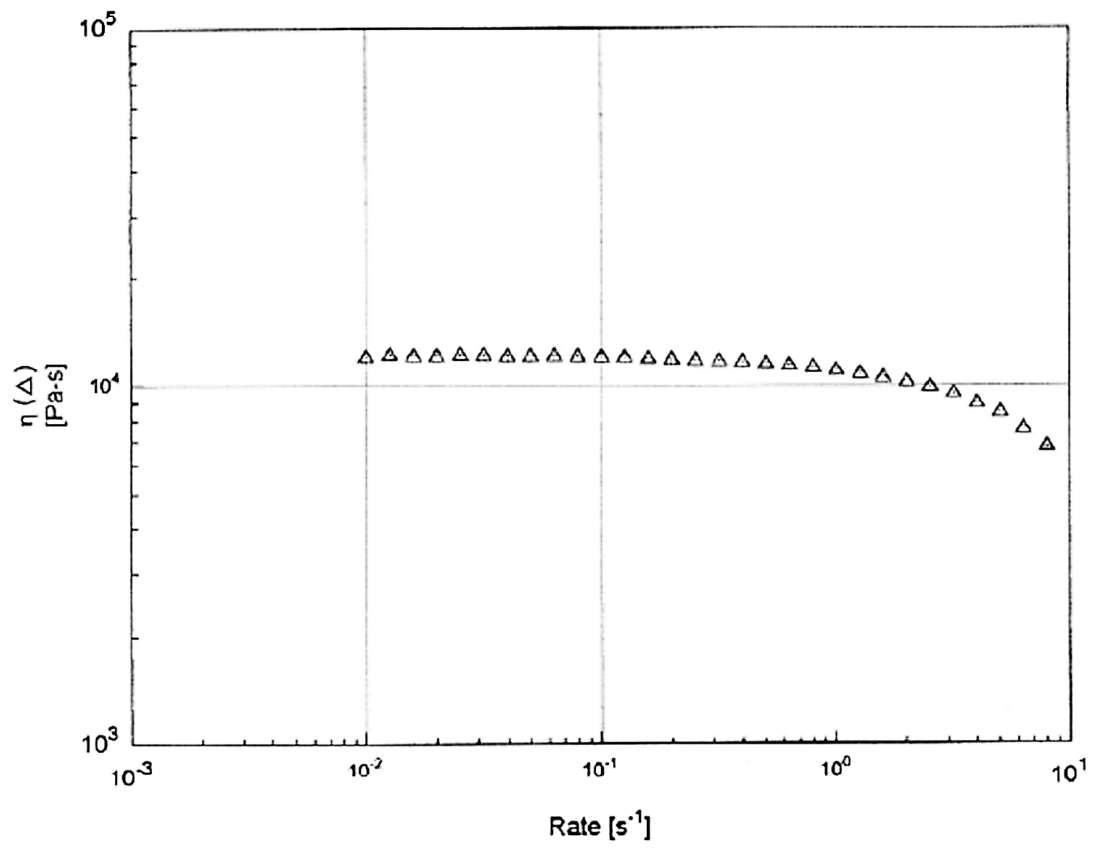

Figure 4. Dependence of complex viscosity of UAO $v s$ shear rate $(\mathrm{rad} / \mathrm{s})$ in the rate sweep mode at $30^{\circ} \mathrm{C}$. UAO did not have organoclay.

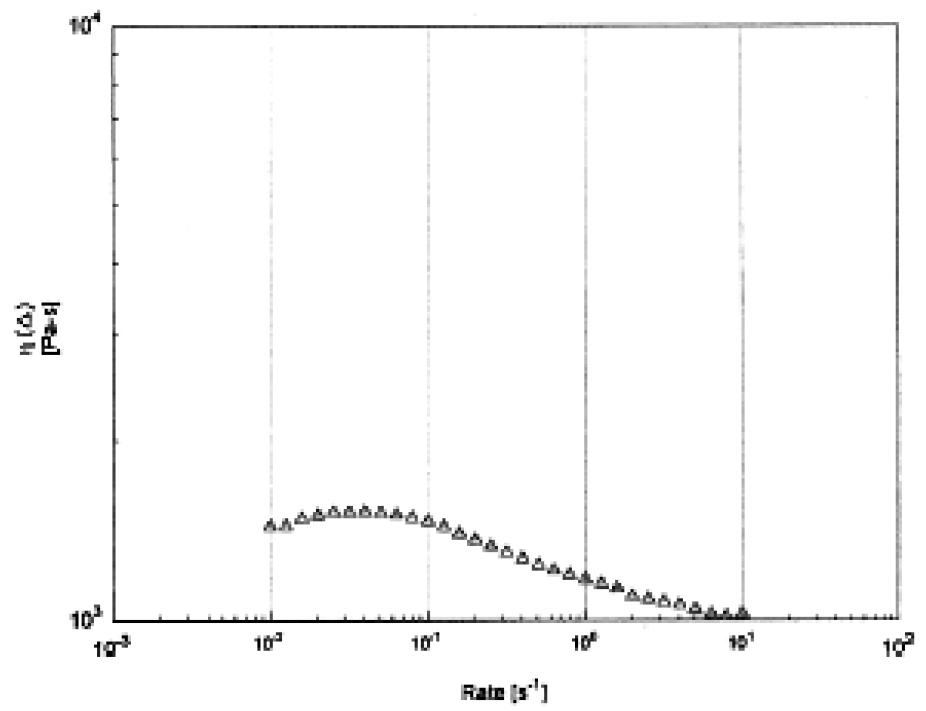

Figure 5. Dependence of complex viscosity of UAO $v s$ shear rate $(\mathrm{rad} / \mathrm{s})$ in the rate sweep mode at $30^{\circ} \mathrm{C}$. UAO had $10.0 \mathrm{wt} \%$ of organoclay.

One should avoid precipitation (crashing, gel formation) of silica in a nanocomposite. In the case of clay all efforts are made to exfoliate clay in polyol or at least 
to intercalate polyol into organoclay, and to get a large aspect ratio. The fact of exfoliation can be verified by XRD and by other techniques.

PU can be obtained by two ways: by radiation cure of urethane acrylates oligomers (pre-polymers) or by dark reactions between diisocyanates and polyols. Radiation cure of urethane acrylates oligomers, and UV-cure in particular, has all of the known advantages over dark cure (high rate, low energy consumption, etc.). The presence of nanofiller, especially well dispersed nanofiller, does not inhibit photoinduced reactions, cf., e.g., Refs [28, 38]. Moreover, photoinitiator intercalated into clay galleries, demonstrates high efficiency (Section 4).

A stunning and often cited result of the Toyota group [17] on nanocomposites expected to find a wide application in automotive industry, 'but this application was stopped because of the high cost' [1]. To the best of our knowledge, this work was never reproduced. Nanocomposites are expected to revolutionize polymer technology. Time will show if it will happen, or not.

\section{Acknowledgements}

The authors at Bomar are grateful to J. A. Leon for fruitful discussions. The Columbia author thanks the National Science foundation for its generous support through Grant CHE 0717518.

\section{References}

1. T. J. Pinnavaia and G. W. Beall, Polymer-Clay Nanocomposites. Wiley, New York, NY (2000).

2. M. Rosoff, Nano-Surface Chemistry. Marcel Dekker, New York, NY (2000).

3. D. R. Paul and L. M. Robeson, Polymer 49, 3187 (2008).

4. B. M. Novak, Adv. Mater. 5, 422 (1993).

5. A. Blumstein, Bull. Chem. Soc., 899 (1961).

6. S. C. Jana and S. Jain, in: Proc. 59th ANTEC (SPE), Vol. 2, p. 2180 (2001).

7. S. Zhou, L. Wu, J. Sun and W. Shen, Progr. Org. Coating. 45, 33 (2002).

8. Z. Wang, P. C. LeBaron and T. J. Pinnavaia, in: 8th Int. Conf. on Polymer Additives, An Addition, p. 10 (1999).

9. P. C. LeBaron, Z. Wang and T. J. Pinnavaia, Appl. Clay Sci. 15, 11 (1999).

10. C. S. Triantafillidis, P. C. LeBaron and T. J. Pinnavaia, Chem. Mater. 14, 4088 (2002).

11. M. K. Sanyal, A. Datta and S. Hazra, J. Marcomol. Sci. Pure Appl. Chem. 74, 1553 (2002).

12. Z. S. Petrović and W. Zhang, Mater. Sci. Forum 352, 171 (2000).

13. I. Javni, Z. S. Petrović and A. Waddon, A. Polyurethanes Expo'98. Dallas, TX, September 17-20 (1998).

14. Z. S. Petrović, I. Javni, A. Waddon and G. Bánhegyi, J. Appl. Polym. Sci. 76, 133 (2000).

15. Y. Chen, S. Zhou, H. Yang and L. Wu, J. Appl. Polymer Sci. 95, 1032 (2005).

16. J. F. Gerard, H. Kaddami and J. P. Pascault, in: Proceedings Eurofillers 97, Manchester, p. 407 (1997).

17. A. Usuki, Y. Kojima, A. Okada, Y. Fukushima, T. Kurauchi and O. Kamigaito, J. Mater. Res. 8, 1179 (1993).

18. J.-H. Chang and Y. U. An, J. Polym. Sci. B 40, 670 (2002). 
19. Z. Wang and T. J. Pinnavaia, Chem. Mater. 10, 3769 (1998).

20. Y. I. Tien and K. H. Wei, J. Appl. Polym. Sci. 86, 1741 (2002).

21. L. Zhu and R. P. Wool, Polymer 47, 8106 (2006).

22. C. H. Dan, M. H. Lee, Y. D. Kim, B. H. Min and J. H. Kim, Polymer 47, 6718 (2006).

23. P. Ni, Q. Wang, J. Li, J. Suo and S. Li, J. Appl. Polymer Sci. 99, 6 (2006).

24. B. Finnigan, P. Halley, K. Jack, A. McDowell, R. Truss, P. Casey, R. Knott and D. Martin, J. Appl. Polymer Sci. 102, 128 (2006).

25. L. T. J. Korley, S. M. Liff, N. Kumar, G. H. McKinley and P. T. Hammond, Macromolecules 39, 7030 (2006).

26. W. J. Seo, Y. T. Sung, S. B. Kim, Y. B. Lee, K. H. Choe, S. H. Choe, J. Y. Sung and W. N. Kim, J. Appl. Polymer Sci. 102, 3764 (2006).

27. J. Jin, M. Song, K. J. Yao and L. Chen, J. Appl. Polymer Sci. 99, 3677 (2006).

28. F. M. Uhl, P. Davuluri, S.-C. Wong and D. C. Webster, Polymer 45, 6175 (2004).

29. A. Pattanayak and S. C. Jana, Polymer 46, 3275 (2005).

30. H. Tan and J. Nie, J. Appl. Polymer Sci. 106, 2656 (2007).

31. A. Pattanayak and S. C. Jana, Polymer 46, 5183 (2005).

32. D. S. Kim, J.-T. Kim and W. B. Woo, J. Appl. Polymer Sci. 96, 1641 (2005).

33. F. Cao and S. C. Jana, Polymer 48, 3790 (2007).

34. S. Solarski, S. Benali, M. Rochery, E. Devaux, M. Alexandre, F. Monteverde and P. Dubois, J. Appl. Polymer Sci. 95, 238 (2005).

35. X. Cao, L. J. Lee, T. Widya and C. Macosko, Polymer 46, 775 (2005).

36. Southern Clay Company website, http://www.nanoclay.com

37. J. Dodge, in: Synthetic Methods in Step-Growth Polymers, Chapter 4, M. E. Rogers and T. E. Long (Eds), p. 197. Wiley, New York, NY (2003).

38. V. Landry, B. Riedl and P. Blanchet, Progr. Org. Coatings 62, 400 (2008). 